of his leg, one of exit on the posterior part of the same surface. This having been looked to, he complained of stiffness in front of the thigb, where I found a lump of small shot under the skia. On searching to find how they got there, I discovered a wound of entry on the back part of the inner face of the thigh and a hollow between it and the shot; so we had two wounds in the leg and a transverse subcutaneous passage; one wound in the thigh with an obliquely

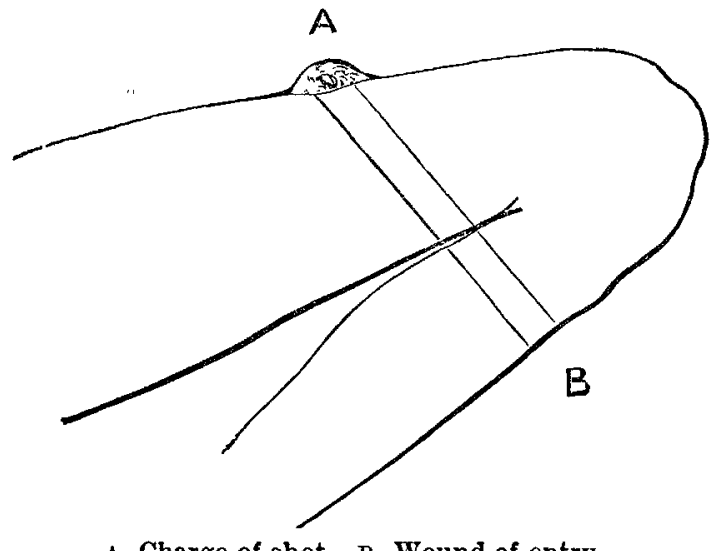

A, Charge of shot. B, Wound of entry.

ascending hollow to the place of lodgement of the shot. Let anyone bend his leg to the full extent on the thigh, and he will at once see that the line of the course of the charge becomes a straight one, as in the above diagram, though the two lines of traverse were so distinct and differing in direction in the straight position of the $\lim b$.

I am, Sir, vours truly, W. W. MOXHAY,

November, 1884 . Surgeon, Royal Berks Hospital.

\section{DEATH DURING THE ADMINISTRATION OF METHYLENE.}

To the Editor of THE LANCET.

SiR,-I beg to report the following case of death under methylene.

John $\mathrm{B} \longrightarrow$, aged nineteen, a miner, was injured six months ago by an explosion of gunpowder while he was "tamping" a hole. A number of pieces of stone were blown into his arm, and his right ulnar nerve was divided. On Sept. 19 ih, he was put under methylene in this hospital, and several pieces of stone were removed. On that occasion he took the anæsthetic perfectly well. On Oct. 17 th he was brought into the theatre for suture of the ulnar nerve, when methylene was given on a leather mask. The parient took the anæsthetic badly from the commencement, struggling violently, and it was with difficulty that anasthesia was induced. The pulse during the induction was good, but on the commencement of the operation the patient became rapidly cyanosed, and the heart's action suddenly ceased, the pulse having given no indication of danger.

A post-mortem examination was made by orcer of the coroner, when the right ventricle was found full of blood, and the left ventricle slightly hypertrophied and contracted. The valves of the heart were quite healthy.

I may raention that a sample of the methylene used was tested, and found to be pure.

I am, Sir, yours faithfully,

W. A. Buchan, M. D., House-Surgeon.

South Deron and East Cornwall Hospital, Plymouth, Nov. 4th, 1881.

\section{EXAMINATION OF ARMY MEDICAL OFFICERS.}

To the Editor of THE LANCET.

SIr,-I do not see that the valuable suggestion made in your issue of the $25 \mathrm{th}$ ult., on the examinations for army medical officers, has attracted the attention it deserves.

With regard to the new examination for Surgeons-Major you offered two suggestions, one of which the revised curcular issued last munth has anticipated, and concerning which therefore no more need be said. The other, and to my mind far the more important of the two, is still a suggestiov, and nothing $m$ ire. It is this: that it should be possible for surgeons-major to take the examination earlier than after twenty years' service. This seems to be a most jadicious proposal and if carried out would remove the only reasonable otjection that can be allered against the examinatiou. That it is a reasonable objection there can be no doubt. As it stands now, an officer his hanging over him this ordeul for rears, and he cannot get through it until he is over forty. Why should this be? The aver tge individual in the forties is taken up with th: practical sice of things, and to have to underyo yet another examination at such an age is an anachrouism which must be particularly irritatiog. He is called upon to renew the days of his youth without being able to feel young. There is a time for everything, and in the fitness of things that for examiuations should end with a man's eighth lustrum at furthest. Why should it not be taken after fifteen years' service inntead of twenty, and so at once get rid of the obly otber remaining objection to the examination? I commend this to the consideration of your readers; and in connexion with your remarks of the 26 ih ult., on the elderly surgeuns-major, who are close on fifty and yet must undergo examination, no doubt the new rules press hardly. I would say to them take a broad view of the subject. As the prin iple underlying these examiuations is recognised as a sound one, it follows that in the interests of the State they should be carried out in practice without delay. Individual interests must yield. but the officers may depend upon it that evidence of good practical knowledge, the natural outcome of their experience in various climates, will be the thing l soked for in the examination, and least of all will it be one of books and cramming.

Nov. 2nd, 1884.

I am, Sir, yours truly,

G.

\section{NORTHERN COUNTIES NOTES. \\ (From our own Correspondent.)}

\section{HOSPITAL ACCOMMODATION IN NEWCASTLE AND} GATESHEAD.

AN important meeting was held at the Newcastle Infirmary on the $6 \mathrm{th}$ inst. to receive the report of a special committee appointed to consider the subject of increased room for patients. The committee recommended very strongly the erection of a new wing on the pres'nt site, and in connexion with the existing building; this, if carried into effect, would dmit of 100 new beds being put up at an expense of probably $£ 25,000$. Lord Ravensworth (who presided) supported the recommendation, and thought that extension of the present building was far more feasible and economical than any project for removal of the infirmary, or, in other words, the erection of a new building. Dr. Gibb also advocated very strongly the retention and extension of the present building. Dr. Heath, on the other hand, along with others, was strongly opposed to the present building, which he thought was objectionable from many points of view, and showed with much force that the present objections would increase ratber thas diminish, and the removal of the buildirg would have to be ultimately faced whatever were done at present. It cannot be disputed that the situation of the Newcastle Infi. mary is about as bad as it could be, regarded from a sanitary or hospital point of view, surrounded as it is by a calte-market goods station of the North-Eastern $R_{\text {dil. }}$ way, and receiving pollution of irs atmosphtre from the smoke of the Tyne, and from the evacuations of many of the factories of Newcastle and Gateshead. Dr. Newcombe of Gateshead writes to our papers to point out that the time is ripe for the extension of the Guteshead Dispensary into an hospital for that borough, and be corstends that the wants of the public would ba better fulfilled, instead of spending a large sum of money on enlarging the Newcastle Infirmary, by bullding a permanent. one in Gateshead in the midst of a teeming population. Many will agree with Dr. Newcombe as to the absolute necessi'y for a hospital in Gateshead, but the whole quesion is opened now, and is certain to be fully gone into, and I shall endeavour to make you aware of the feeling on the subject as regards both sides of the Tyne.

SMALL-POX IN THE CITY OF DURHAM.

There is as yet no sign of any subidence of the small.pox epidemis in Durbam, which has become very serious and is having a disastrous effect on the trade of the place, a matter of much consequence at the present time. A public meeting has been held calling on the sanitary authority to provide adequate hospital accommodation, and the Dean and Chapter 